\title{
Genetic characterization of a Marek's disease virus strain isolated in Japan
}

\author{
Shiro Murata ${ }^{1,2^{*}} \mathbb{0}$, Yuka Machida ${ }^{1}$, Masayoshi Isezaki ${ }^{1}$, Naoya Maekawa², Tomohiro Okagawa ${ }^{2}$, Satoru Konnai ${ }^{1}, 2$ \\ and Kazuhiko Ohashi ${ }^{1,2}$
}

\begin{abstract}
Background: Marek's disease virus (MDV) causes malignant lymphomas in chickens (Marek's disease, MD). MD is currently controlled by vaccination; however, MDV strains have a tendency to develop increased virulence. Distinct diversity and point mutations are present in the Meq proteins, the oncoproteins of MDV, suggesting that changes in protein function induced by amino acid substitutions might affect MDV virulence. We previously reported that recent MDV isolates in Japan display distinct mutations in Meq proteins from those observed in traditional MDV isolates in Japan, but similar to those in MDV strains isolated from other countries.

Methods: To further investigate the genetic characteristics in Japanese field strains, we sequenced the whole genome of an MDV strain that was successfully isolated from a chicken with MD in Japan. A phylogenetic analysis of the mea gene was also performed.

Results: Phylogenetic analysis revealed that the Meq proteins in most of the Japanese isolates were similar to those of Chinese and European strains, and the genomic sequence of the Japanese strain was classified into the Eurasian cluster. Comparison of coding region sequences among the Japanese strain and MDV strains from other countries revealed that the genetic characteristics of the Japanese strain were similar to those of Chinese and European strains.

Conclusions: The MDV strains distributed in Asian and European countries including Japan seem to be genetically closer to each other than to MDV strains from North America. These findings indicate that the genetic diversities of MDV strains that emerged may have been dependent on the different vaccination-based control approaches.
\end{abstract}

Keywords: Marek's disease virus, Marek's disease, Meq, Japanese strain, Whole genome sequencing

\section{Background}

Marek's disease virus (MDV; family, Herpesviridae; subfamily, $\alpha$-Herpesvirinae; genus, Mardivirus; species, Gallid alphaherpesvirus 2) is the causative agent of Marek's disease (MD), which manifests as malignant lymphomas in infected chickens [1]. MD previously caused serious economic losses to the poultry industry, but the introduction of vaccines has led to its successful control [2]. Attenuated strains of MDV and the naturally

*Correspondence: murata@vetmed.hokudai.ac.jp

${ }^{1}$ Department of Disease Control, Faculty of Veterinary Medicine, Hokkaido University, Kita-18, Nishi-9, Kita-ku, Sapporo 060-0818, Japan

Full list of author information is available at the end of the article non-oncogenic Gallid alphaherpesvirus 3 and Meleagrid alphaherpesvirus 1 (turkey herpesvirus, HVT) have been used as monovalent or multivalent vaccines. An attenuated MDV strain, CVI988, is considered the most protective vaccine currently available and has been introduced in many countries [3]. However, the virulence of MDV field strains has a tendency to increase, and pathogenic MDV strains are generally classified as mild, virulent, very virulent, and very virulent + [4]. Currently, sporadic occurrences of MD are still reported in some countries [4-11], and highly virulent MDV strains could potentially cause future outbreaks despite vaccination [4].

The Meq protein, which is highly expressed in MDVtransformed cell lines and tumor samples [12-15], is an original author(s) and the source, provide a link to the Creative Commons licence, and indicate if changes were made. The images or other third party material in this article are included in the article's Creative Commons licence, unless indicated otherwise in a credit line to the material. If material is not included in the article's Creative Commons licence and your intended use is not permitted by statutory regulation or exceeds the permitted use, you will need to obtain permission directly from the copyright holder. To view a copy of this licence, visit http://creativecommons.org/licenses/by/4.0/. The Creative Commons Public Domain Dedication waiver (http://creativeco mmons.org/publicdomain/zero/1.0/) applies to the data made available in this article, unless otherwise stated in a credit line to the data. 
oncoprotein of MDV. Its structure consists of an N-terminal basic region leucine zipper (bZIP) domain and a C-terminal transactivation domain. The bZIP domain, similar to that of the Jun/Fos family of oncoproteins, consists of two stretches of basic residues (basic regions 1 and 2) and a leucine zipper, whereas the transactivation domain is characterized by proline-rich repeats that contain several SH3-binding motifs [16]. Meq can form dimers via the leucine zipper and interact with the promoter region of target genes through the basic region, thereby regulating gene expression in host cells and MDV [16]. In addition, Meq can interact with p53 [17] and the C-terminal binding protein [18], ultimately affecting characteristics of transformation such as antiapoptotic effects and regulation of gene expression. Thus, Meq plays important roles in transformation induced by MDV and is essential for viral pathogenesis.

Genetic approaches have revealed polymorphisms in Meq proteins among MDV strains isolated in USA and that they are associated with MDV virulence [19]. Amino acid substitutions can affect Meq protein functions, transactivation activities, and transformation [20, 21]. The evolution of meq genes is comparable with the evolutionary rate of RNA viruses, and the time of meq gene divergence is related to the transitions in management practices in the poultry industry, including the introduction of vaccines [23]. Thus, the positive selection induced by vaccination seems to be a reason for the emergence of genetic diversity in the $m e q$ gene [23]. To date, $m e q$ gene sequences in several regions other than the USA, including China, Europe and Australia, have been investigated [5, 24-31]. The meq genes in MDV strains isolated in each region were found to exhibit different genetic characteristics [23]. Thus, meq gene polymorphisms or evolution seem to reflect the geographical characteristics and the history of vaccine use in each region.

Whole-genome sequences of MDV strains isolated in some regions have been reported from the 2000s. The attenuated MDV vaccine strain, CVI988 [32], MDV strains with different virulence in the USA [33-38], pathogenic and vaccine strains in China [39-44], and a pathogenic strain in Europe $[45,46]$ were sequenced. Phylogenetic analysis indicated that most MDV strains can be classified into two clusters, namely, the North American or Eurasian clusters, and the estimated timescaled phylogeny suggested that MDV virulence evolved independently in Eurasia and North America [46]. CVI988 was initially isolated and developed in Europe as a vaccine and is used worldwide. However, in the USA, HVT was initially used for the prevention of MD, and a bivalent vaccine comprising HVT and SB-1 (naturally non-oncogenic Gallid alphaherpesvirus 3) has been adopted after outbreaks in HVT-vaccinated chickens.
Therefore, the history of vaccine control seems to affect the differential evolution of MDV strains in each continent [46].

In Japan, MD occurrences are sporadic. We previously reported the sequences of meq genes in MDV isolates in Japan and that the amino acid sequence at position 176 is serine or threonine in the most recent field isolates [22]. This amino acid sequence was found to be unique to Japanese isolates, and the sequences of $m e q$ are genetically closer to those of Chinese isolates [22]. To identify the properties of MDV strains distributed in Japan, we previously isolated a field strain of MDV from chickens that showed clinical signs of MD. The isolated strain Kgsc1 was not contaminated by the three types of vaccine strains [47]. However, the genetic characteristics of Kgs$\mathrm{c} 1$, except for the meq gene, is still unknown. Therefore, in this study, to investigate the genetic characteristics of Kgs-c1, we performed whole-genome sequencing. We also compared the sequences with those of MDV strains isolated in other countries.

\section{Methods \\ Virus}

An MDV strain, Kgs-c1, was isolated in 2014 from a poultry farm in Japan, in which some chickens had developed signs of MD [47]. Day-old-chicks from the same farm were vaccinated with CVI988, an attenuated GaHV-2 vaccine strain [47]. PCR analysis, which targeted the meq gene to detect CVI988 and specific genes to detect other vaccine strains and chicken anemia virus, revealed that Kgs-c1 was not contaminated with vaccine strains and chicken anemia virus (data not shown). Kgsc1 was passaged 12 times in chicken embryo fibroblasts (CEFs) to obtain sufficient amounts of the virus genome for analysis.

\section{DNA preparation}

Total cellular DNA samples were extracted from CEFs infected with Kgs-c1 as previously described [48]. In brief, the infected CEFs were immersed overnight at $55{ }^{\circ} \mathrm{C}$ in $1 \mathrm{ml}$ of lysis buffer $(0.5 \%$ SDS, $0.1 \mathrm{M} \mathrm{NaCl}$, $10 \mathrm{mM}$ tris $\mathrm{pH}$ 8.0, $1 \mathrm{mM}$ EDTA) containing proteinase $\mathrm{K}$ at a final concentration of $200 \mu \mathrm{g} / \mathrm{ml}$. Total cellular DNA was extracted with phenol-chloroform-isoamyl alcohol (25:24:1), precipitated with ethanol, and treated with RNase A at a final concentration of $20 \mu \mathrm{g} / \mathrm{ml}$.

\section{Whole-genome sequencing of Kgs- $\mathrm{c} 1$}

The concentration of total cellular DNA was determined using a Qubit Fluorometer (Invitrogen, CA, USA) and Agilent 220 TapeStation System. The total cellular DNA was used to create a library, by using the TruSeq ChIP Sample Prep Kit (Illumina K.K.). Library preparations 
were sequenced with an Illumina HiSeq with 100base paired-end reads. All the kits described were used according to the manufacturers' instructions. All procedures were performed by Hokkaido System Science Co. Ltd, Hokkaido, Japan.

\section{Read mapping to a reference sequence and mutation analysis}

The paired-end read output from HiSeq was subjected to adaptor-trimming using cutadapt (version 1.1) (http:// code.google.com/p/cutadapt/) and quality-trimmed using Trimmomatic (version 0.32) (http://www.usade llab.org $/ \mathrm{cms} /$ ?page=trimmomatic). The resulting reads were mapped to a reference sequence from RB-1B, which is a well-characterized virulent strain of MDV (accession number: EF523390) [37, 49-51] (accession number: EF523390), using Burrows-Wheeler Aligner (version 0.7.10) (http://bio-bwa.sourceforge.net/), and the output alignment data were sorted using SAMtools $\mathrm{V}$ (version 1.2) (http://www.htslib.org/man/samtools/) and the Genome Analysis Toolkit (Lite version 2.3.0) (https://www.broadinstitute.org.gatk/). The differences in nucleotide sequences between the Kgs- $\mathrm{c} 1$ and RB-1B genomes were identified using SAMtools V (version 1.2) and BCFtools (version 1.2) (https://www.htslib.org/man/ bcftools/), and the consensus sequence of Kgs-c1 (accession number: LC589272) was determined based on the results of read-mapping and comparison with the RB- $1 B$ genome. The allele frequencies of the mapped reads were higher than $99 \%$ in all of the open reading frames from the consensus sequence. All the above-mentioned procedures were performed by Hokkaido System Science Co. Ltd.

\section{Genetic analysis of the meq and UL36 genes and the MDV genomes}

Phylogenetic analysis of the meq gene was performed using MDV isolates from several countries including Japan, USA, China, other Asian countries, Europe, and Australia. The sequences were aligned using MAFFT version 7 [52], and the tree was constructed with MEGA7 software [53], using the minimum evolution algorithm [54]. Information about the meq genes used for the analysis is provided in Additional file 1: Table S1. Unique long (UL) to unique short (US) (UL-internal repeat long (IRL)-internal repeat short-UL) sequences from 26 MDV strains were aligned using MAFFT, and the tree was generated using the minimum evolution algorithm of MEGA 7 software. The UL36 genes and the variable regions of the deduced amino acid sequences of the UL36 proteins were aligned using MAFFT. A phylogenetic tree based on UL36 genes from 26 MDV strains, which were used for the phylogenetic analysis of UL-US sequences, was generated using the minimum evolution algorithm of MEGA 7 software. The MDV strains and their accession numbers used for this analysis are listed in Table 1.

\section{Results \\ Genome organization of the Japanese strain Kgs-c1 and comparison of genome sequences between $\mathrm{Kgs-c1}$ and RB-1B}

The whole-genome sequence of Kgs-c1 was analyzed, and the obtained reads were mapped to the genome of the RB-1B strain, a well-characterized vv MDV strain [37, 49-51]. The consensus sequence was determined, and the length of the viral genome was estimated to be 174,999 bp. Non-synonymous differences were found in several genes between Kgs-c1 and RB-1B. Except for MDV049 (UL36), multi-polymorphisms were found in MDV005 (meq), MDV084 (ICP4), MDV095 (glycoprotein I), and MDV096 (glycoprotein E) (Table 2). In most cases, the differences found based on comparison with the RB-1B genome were similar to those found in the sequences of some strains from Europe and China, whereas they were different from those found in most of US strains. In contrast, the polymorphisms found near the junction between repeat long and UL sequences were unique to Kgs-c1 (MDV006-019; Table 2). An amino acid deletion was found in MDV013 (glycoprotein L)/MDV013.5 (MHC class II beta chain binding protein) (Table 3). A four-amino acid deletion was found in MDV013/MDV013.5, and this deletion was not observed in MDV013/013.5 of other strains. In MDV056 (probable membrane protein), the amino acid residues at positions 136 and 137 of RB-1B are asparagine and methionine, respectively, whereas the amino acid sequence in Kgsc1 included lysine at position 136 and an amino acid was deleted. However, MDV056 sequences in Chinese and European strains were the same as those in Kgs-c1 (Table 3).

\section{Phylogenetic analysis of the sequences from UL to US regions}

The sequence of the Kgs-c1 genome, except for the terminal repeat long and terminal repeat short regions, was subjected to phylogenetic analysis. In this study, because we used a large number of nucleotides for phylogenetic analysis, the enormous computational time required is a challenge, especially for the maximum likelihood method [55]. Therefore, to analyze the genetic characteristics of the Kgs-c1 genome, we employed methods based on the minimum evolution principle [54]. The MDV strains formed two clusters, the Eurasian and North American clusters (Fig. 1). The genome of Kgs-c1 was classified into the Eurasian cluster, and these results were consistent with the results obtained by comparing the coding 
Table 1 MDV strains used for the analyses in this study

\begin{tabular}{|c|c|c|c|c|c|}
\hline Country & Strain & Virulence & Genome size (bp) & Accession No & References \\
\hline Japan & Kgs-c1 & - & 174,999 & LC589272 & This study \\
\hline \multirow[t]{6}{*}{ USA } & $648 a$ & $v v+$ & 176,080 & JQ806361 & Spatz et al. [36] \\
\hline & Md5 & vv & 177,874 & NC_002229 & Tulman et al. [38] \\
\hline & Md11 & vV & 170,950 & AY510475 & Niikura et al. [34] \\
\hline & RB-1B & vv & 178,246 & EF523390 & Spatz et al. [37] \\
\hline & GA & $v$ & 174,077 & AF147806 & Lee et al. [33] \\
\hline & $\mathrm{CU}-2$ & $\mathrm{~m}$ & 176,922 & EU499381 & Spatz et al. [35] \\
\hline \multirow[t]{13}{*}{ China } & GX0101 & vV & 178,101 & JX844666 & Su et al. [42] \\
\hline & LMS & vv & 177,526 & JQ314003 & Cheng et al. [39] \\
\hline & 814 & m/vaccine & 172,541 & $J F 742597$ & Zhang et al. [44] \\
\hline & CC/1409 & - & 175,561 & KU744560 & Lv et al. [41] \\
\hline & HNGS101 & - & 175,888 & MG432697 & He et al. [40] \\
\hline & HNLC503 & - & 178,195 & MG518371 & - \\
\hline & $\mathrm{HS} / 1412$ & - & 175,532 & KU744561 & Lvet al. [41] \\
\hline & $J-1$ & - & 176,118 & KU744555 & Lv et al. [41] \\
\hline & $J L / 1404$ & - & 176,083 & KU744559 & Lv et al. [41] \\
\hline & LCC & - & 175,525 & KU744556 & Lvet al. [41] \\
\hline & LCY & - & 175,319 & KX290013 & Zhang et al. [43] \\
\hline & LTS & - & 176,023 & KU744557 & Lvet al. [41] \\
\hline & WC/1203 & - & 176,057 & KU744558 & Lvet al. [41] \\
\hline Poland & Polen5 & $h v^{* *}$ & 177,821 & MF431496 & Trimpert et al. [46] \\
\hline Israel & EU-1 & hv & 177,828 & MF431494 & Trimpert et al. [46] \\
\hline Hungary & ATE2539 & $\mathrm{vv}+$ & 177,868 & MF431493 & Trimpert et al. [46] \\
\hline England & pC12:130 & vv & $183,850^{*}$ & FJ436096 & Spatz et al. [45] \\
\hline Hungary & MD70/13 & v & 177,844 & MF431495 & Trimpert et al. [46] \\
\hline Netherland & CVI988 & m/vaccine & 178,311 & DQ530348 & Spatz et al. [32] \\
\hline
\end{tabular}

* The length of $\mathrm{pC12:130}$ genome contains a vector sequence

** Hyper virulent (hv): Recent field strains isolated in Europe with a history of high virulence but not pathotyped within $\mathrm{m}-\mathrm{vv}+\mathrm{grading}$ scheme [46]

regions among MDV strains (Tables 2 and 3). Therefore, the ancestor of Kgs-c1 might be closer to the Chinese and European strains than to the US strains. In the Eurasian cluster, however, Kgs-c1 seemed to belong to a different branch from pathogenic strains of China and Europe, although the number of available sequences was limited.

\section{Phylogenetic analysis of the meq genes}

The meq genes from MDV strains isolated from various countries of North America, Europe, Asia, Africa, South America, and Oceania formed three major clusters as follows: North America, other regions including Europe, Asia, Africa, and South America as well as L-meq (these meq genes contained insertions in the transactivation domains; Fig. 2). The sequence of the meq gene in Kgs-c1 was most frequently observed in MDV isolates in Japan [22], and therefore, most meq genes from Japanese isolates belonged to the other regions' cluster. However, the meq genes from some isolates in Europe and Asia were classified into the North American cluster.
Thus, some MDV strains, which harbor meq, indicative of similar genetic characteristics to those of US isolates, seem to be present in other countries as well. Strains of low virulence and pathogenic strains from Australia and Italy were mainly classified to the third cluster, L-meq. Geographical features and the correlation with virulence were not found in the cluster, because an insertion could largely affect the formation of the cluster.

\section{Comparison of the UL36 genes}

When we compared the sequences of the coding regions of MDV strains, the variable regions in the UL36 proteins were the most diverse (Additional file 2: Fig. S1). As a different feature of MDV UL36 proteins from those of other herpesviruses, the variable region is present near the $\mathrm{C}$-terminus and its sequences are different among MDV strains [56]. The variable regions in the UL36 proteins of MDV consisted of two types of repeat sequences, $\mathrm{KP}(\mathrm{T} / \mathrm{S} / \mathrm{P}) \mathrm{PA}(\mathrm{S} / \mathrm{P})$ and $\mathrm{KPKPPP}(\mathrm{D} / \mathrm{A} / \mathrm{T}) \mathrm{PD}(\mathrm{F} / \mathrm{S})$ (Additional file 3: Table S2, Additional file 2: Fig. S1). When we 


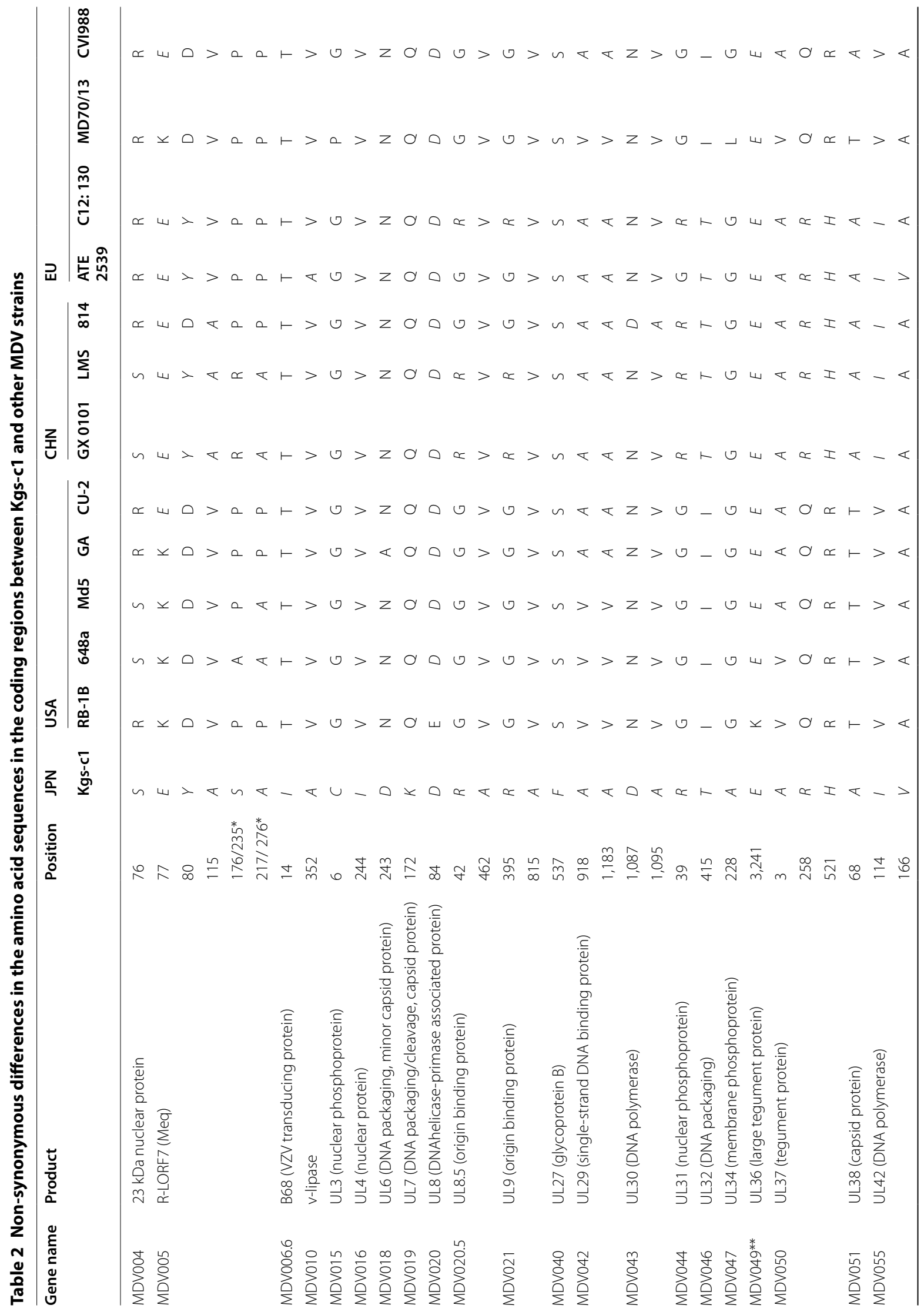




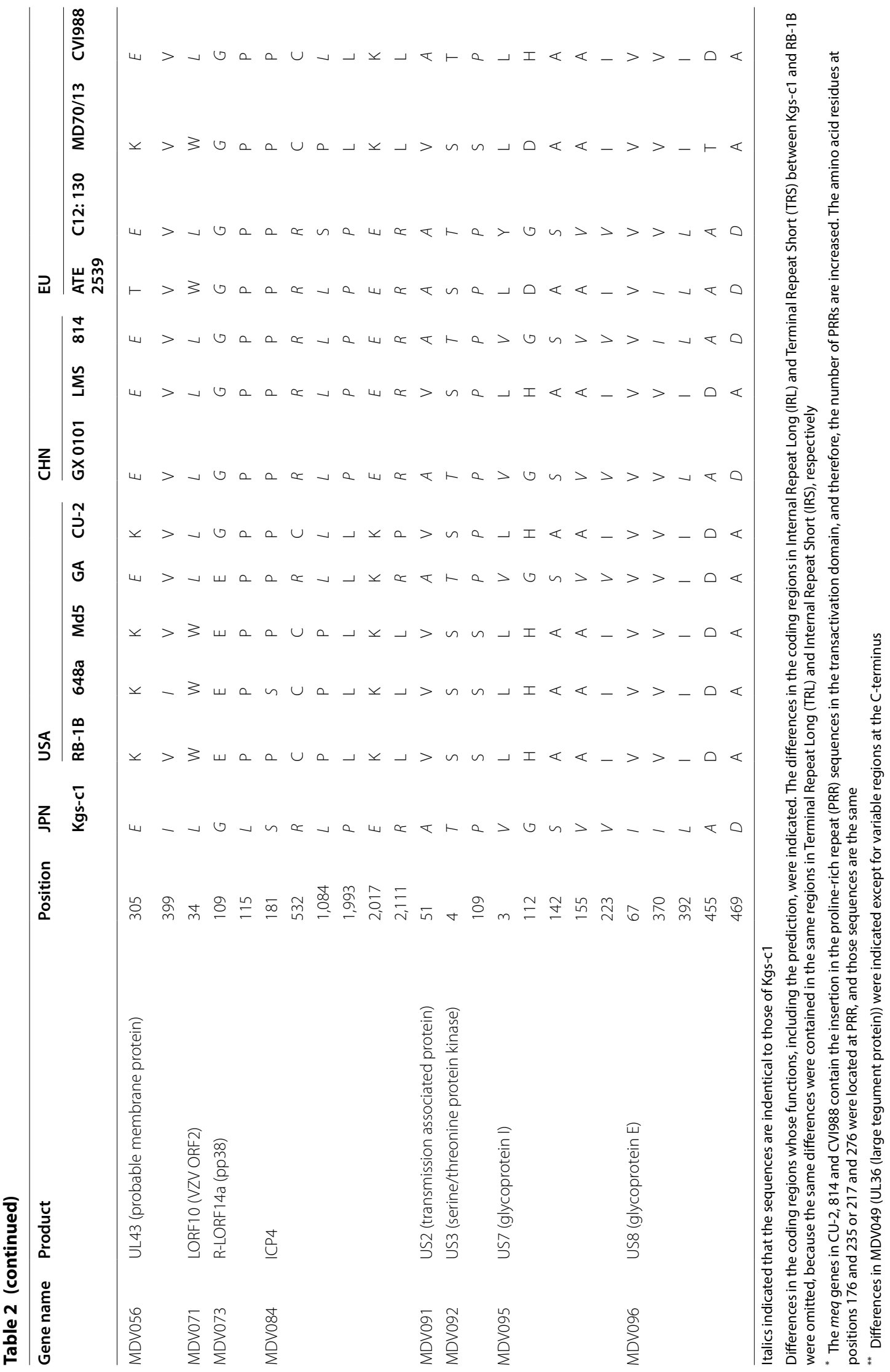




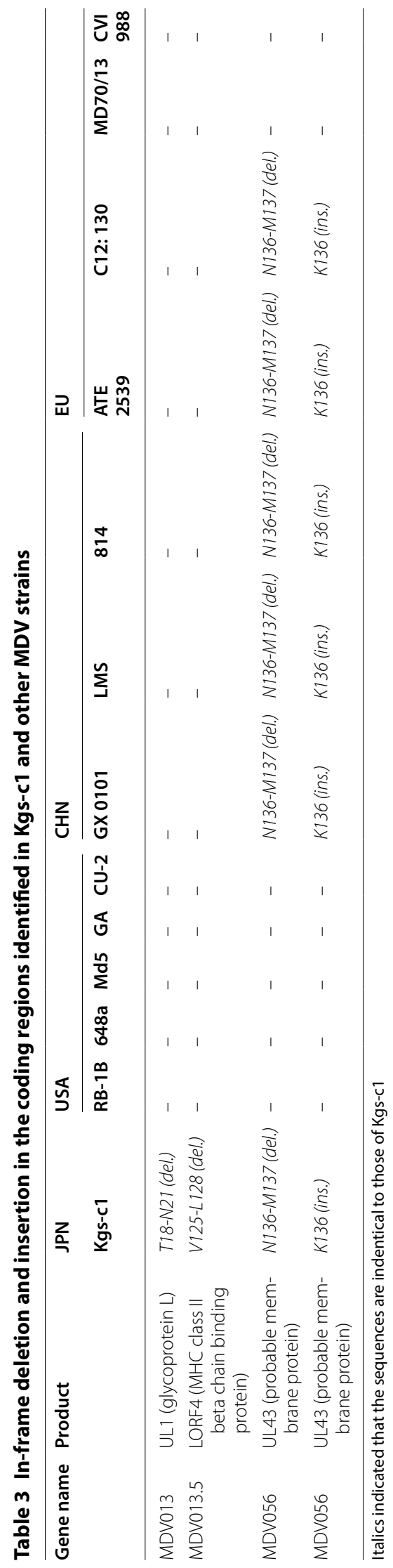




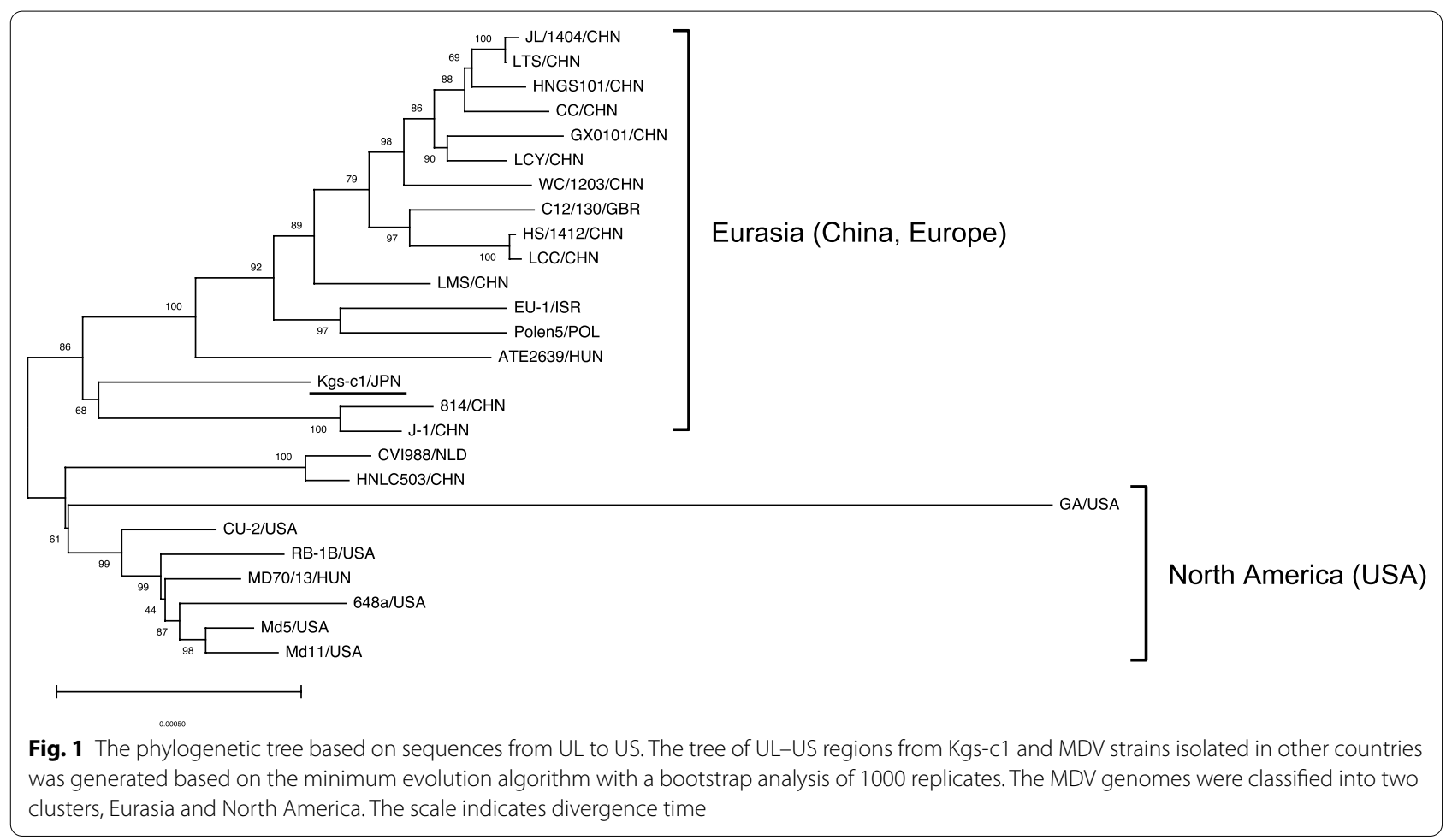

compared the sequences of the variable regions among MDV strains, no trend in the number of repeat sequences was observed, correlating with the virulence (Additional file 3: Table S2). When we analyzed the phylogeny of the UL36 genes from the same MDV strains used for the analysis of the UL-US regions (Fig. 1), we found that the sequences of the UL36 genes were classified into two clusters, North America and Eurasia (Fig. 3). Unlike the meq genes from isolates of the UL-US regions, the UL36 gene from Kgs-c1 belonged to the North American cluster, suggesting that Kgs-c1 partially has genetic characteristics different from MDV strains isolated in Eurasian countries.

\section{Discussion}

MD is currently well-controlled by vaccination, although it previously caused serious economic losses to the poultry industry. However, the virulence and genetic characteristics of MDV strains have changed over time, and divergence seems to be correlated with the introduction of vaccines [23, 46]. According to a previous report, the genome sequences of MVD strains are classified into two main clusters, Eurasia and North America [46]. The genome sequences of MDV strains isolated in USA, China, and Europe have been investigated [32-46]. However, data on the whole genome sequences of MDV strains from other regions are limited. We previously reported changes in the genetic characteristics of meq genes in Japanese isolates [22]. In the present study, to compare the genetic characteristics of the whole genome of MDV strains circulating in Japan, we analyzed the whole genome sequence of a Japanese field strain, Kgs-c1, isolated in 2014.

The distinct diversity of the meq gene has been considered to be correlated with the enhanced virulence of MDV strains $[19,23]$. The $m e q$ gene is thought to be associated with the evolution of MDV virulence, and non-synonymous mutations are frequently observed in meq genes among MDV strains [46]. To date, sequences of the meq genes from MDV strains from various countries have been reported [5, 24-31]. In the present study, the UL-US regions of MDV strains were divided into two clusters, Eurasia and North America, as previously reported [46], whereas the meq genes of MDV strains from various regions formed three clusters, North America, other regions including Eurasian countries, and L-meq. Unfortunately, most of the whole genome sequences of MDV strains for which meq genes were classified into the L-meq cluster, in the phylogenetic analysis of the meq gene, were not available. However, the L-meq genes of strains 814 and CU-2, which were classified into Eurasia and North America groups, respectively, possess an insertion in the transactivation domain, and therefore, these L-meq genes seemed to be classified into the L-meq cluster in this phylogenetic analysis. Thus, the meq gene and UL-US region seem to indicate similar phylogeny, 
(See figure on next page.)

Fig. 2 Phylogenetic trees based on alignment of meg genes from Kgs-c1 and MDV strains. The tree was generated using the minimum evolutionary algorithm with a bootstrap analysis of 1000 replicates. The meq genes used in this analysis were mainly classified into three clusters, North America, other regions including Eurasian countries, and L-meq. Numbers indicate bootstrap percentages (1000 replicates). Arrow heads indicate MDV strains used for the phylogenetic analysis described in Fig. 1. The scale indicates divergence time

except for the appearance of the L-meq cluster. The meq gene of Kgs-c1, for which the sequence is frequent among Japanese MDV strains, was classified into the cluster of other regions. In addition, the UL-US region of Kgs-c1 was classified into the Eurasian cluster. Taken together, the genetic characteristics of MDV strains distributed in Japan might be largely classified into the Eurasian cluster, similar to that observed with Kgs-c1. However, some $m e q$ genes from Japanese isolates were classified into the North American cluster. Therefore, it is possible that MDV strains with genetic characteristics similar to those of US strains are also present in Japan.

A deletion of amino acid sequences was found in MDV013 (glycoprotein L)/MDV013.5 (MHC class II beta chain binding protein) and MDV056 (probable membrane protein). The deletion in MDV013/MDV013.5 was also found in some highly virulent strains [19]. However, this deletion does not seem to be correlated with increased virulence $[57,58]$. The Chinese and European strains showed a deletion in the same region of MDV056 [32, 39-46]. However, this deletion was also found in the vaccine strain 814 and therefore, it might not affect virulence, although its correlation with MD pathogenesis is unclear.

The historical background related to the introduction of vaccines in each country is different, and this seems to be correlated with differences in the evolution of MDV genomes in each country [46]. In Japan, HVT was initially approved for protection from MD in 1972. A few years after the initial introduction of HVT, field outbreaks were sporadically observed in HVT-vaccinated chickens. Therefore, other types of vaccines, specifically CVI988 in 1985 and a bivalent vaccine comprising CVI988 and HVT in 1988, were approved. Thereafter, CVI988 and multivalent vaccines including CVI988 have been widely used to prevent MD occurrences in poultry farms in Japan. In Europe, HPRS-16, which is an MDV strain that was originally isolated in the UK, was initially used as a live-attenuated vaccine [2]. Later, a vaccine derived from an attenuated MDV strain, CVI988, was used; currently, this vaccine is being used globally [2]. In contrast, in the USA, HVT was initially developed as a live vaccine [2]. In addition, a naturally non-pathogenic strain, SB-1, was isolated in the USA in the late 1970s, and has been used as a bivalent vaccine to enhance the vaccine efficacy of HVT [2]. The historical background related to the use of vaccines between Europe and the USA is thus different, and the background of Japan is closer to that of Europe. Thus, the use of vaccines could induce the evolution of MDV strains in each country, and Japanese strains seemed to develop genetic characteristics similar to those of European strains.

The UL36 protein, a large tegument protein encoded by a member of Herpesviridae, is known to form the innermost layer of the complex protein scaffold between the capsid and envelope [59]. MDV encodes a ubiquitinspecific protease as part of the $\mathrm{N}$-terminal region of the UL36 protein, similar to that observed in other known herpesviruses [60]. The UL36 protein was found to be correlated with the tumorigenic activity and replication of MDV via the deubiquitinase activity of the ubiquitinspecific protease $[60,61]$. In contrast, MDV encodes unique repeat sequences at the C-terminal region [56]. Phylogenetic analysis revealed that the UL36 gene of Kgs-c1 was classified into the North American cluster, unlike those of the meq gene and UL-US region. In addition, Kgs-c1 exhibited unique sequences in the coding regions at the $5^{\prime}$ regions of the UL region. Thus, Kgs-c1 might have undergone evolutionary processes different from those of other pathogenic strains, although Kgs$\mathrm{c} 1$ is closer to Chinese and European strains than to US strains in terms of the whole genome sequence.

For the phylogenetic analysis, methods based on the maximum likelihood principle have been often applied, as their accuracy is generally higher than that of other methods. However, these methods require much longer time, and some factors, such as the number of nucleotides, the number of sequences, and the model used for analysis, often affect accuracy [55]. Therefore, when using these methods, optimization should be considered. In addition, many empirical studies have indicated that other methods, including the minimum evolution principle, provide similar phylogenetic inference by applying the bootstrap test [55]. A previous study reported that in metagenomic analysis, phylogenetic classification using the novel method (PhyClass) based on the minimumevolution principle was as efficient as that with the maximum likelihood methods [62]. Therefore, in the present study, the genetic characteristics of the Kgs-c1 genome were analyzed using the minimum-evolution method. However, its accuracy might be less than those using the best existing maximum likelihood methods with 


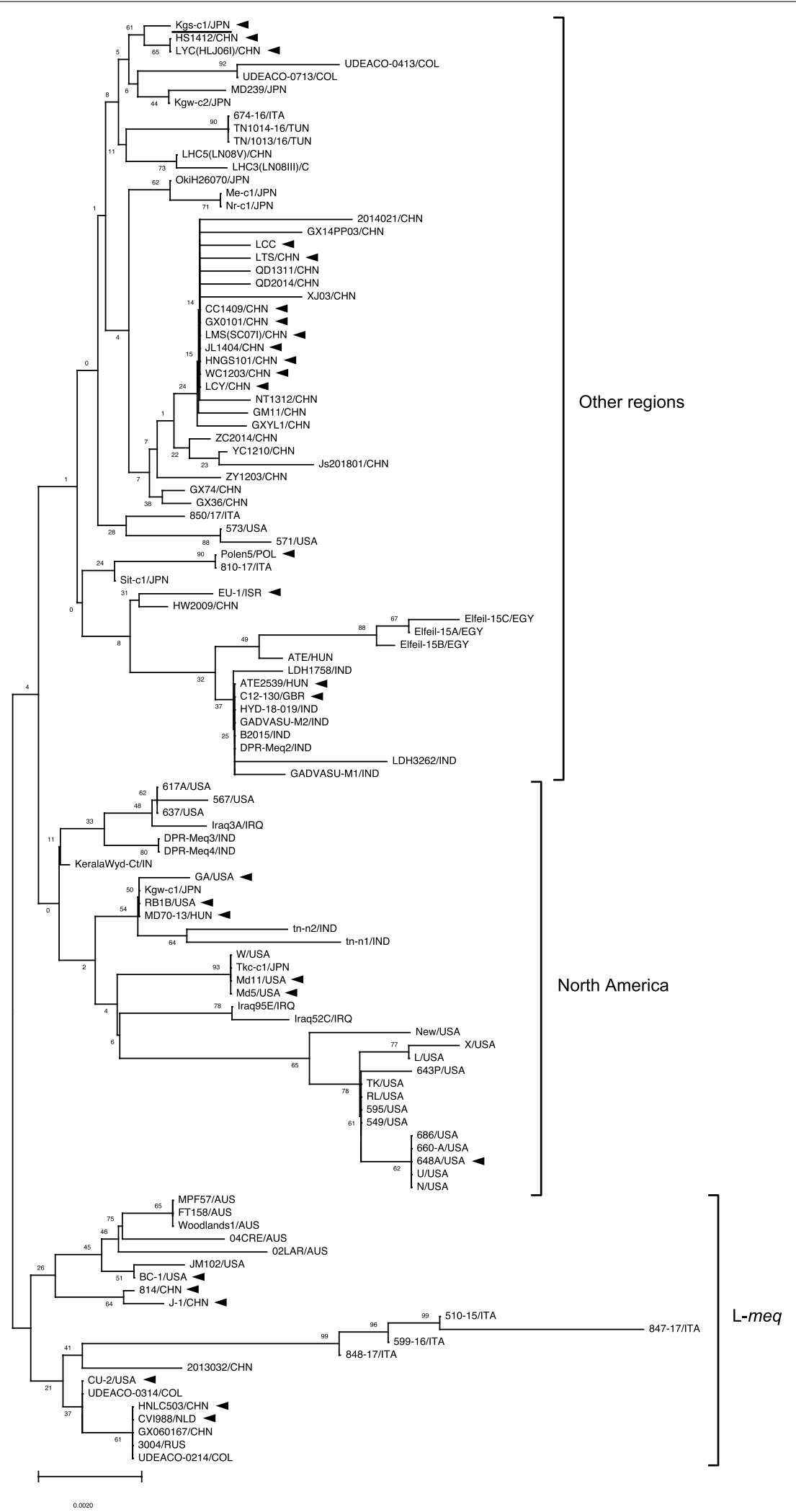




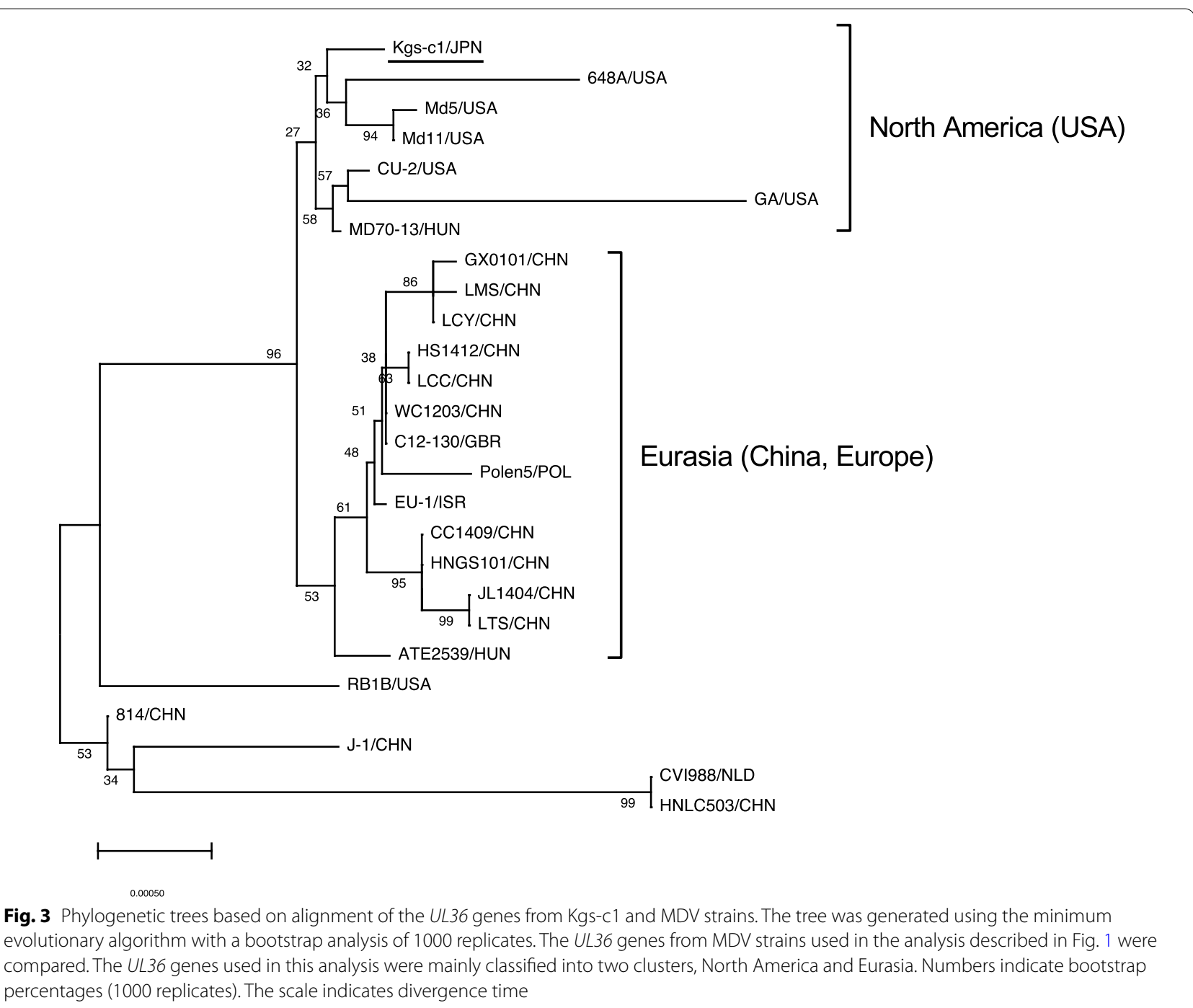

optimized models. Therefore, other approaches should be applied to analyze the phylogeny of Kgs-c1 more accurately, and assess the biases by the minimum-evolution method.

\section{Conclusion}

In this study, we investigated the genomic characteristics of a Japanese MDV strain, namely Kgs-c1, by analyzing its whole genome sequence. The genomic features of Kgs-c1 were largely related to those of Chinese and European strains, rather than US strains. In Japan, CVI988 has been widely used to prevent MD occurrences, and therefore, this study supports the hypotheses that the historical background of vaccine use affects the evolution of MDV strains and that MDV strains adapt to the immunity induced by vaccination to be distributed in the field. However, the genome sequence of Kgs-c1 partially indicates unique characteristics in some coding regions.
Thus, the ancestor of MDV strains distributed in Japan, China, and Europe seems to be closer to each other than to strains from the USA, but the evolution of Japanese strains might be unique.

\section{Supplementary information}

Supplementary information accompanies this paper at https://doi. org/10.1186/s12985-020-01456-1.

Additional file 1: Table S1. The meq genes used for analyses in this study.

Additional file 2: Fig. S1. Alignment of the deduced amino acid sequences of the variable regions of UL36 proteins. The variable regions in the UL36 proteins from Kgs-C1 and MDV strains isolated in other countries were aligned. Shaded fields in gray indicate the repeat sequence of "KP (T/S/P)PA(S/P)", and a solid line indicates each repeat sequence. The different colors of the letters indicate each type of the repeat sequence of "KP (T/S/P)PA(S/P)". Patterned fields indicate the repeat sequence of "KPKPPP(D/A/T)PD(F/S)", and a dotted line indicates each repeat sequence. The number of each repeat sequence is summarized in Additional file 1: Table 51. 
Additional file 3: Table S2. Number of repeat sequences in the UL36 proteins.

\section{Abbreviations}

MDV: Marek's disease virus; MD: Marek's disease; HVT: Turkey herpesvirus; bZIP: Basic leucine zipper; CEF: Chicken embryo fibroblast; UL: Unique long; US: Unique short; IRL: Internal repeat long.

\section{Acknowledgements}

We thank Drs. Akira Taneno and Eishi Sakai, Vaxxinova Japan K.K., Tokyo, Japan, for their helpful advice. We would like to thank Editage (www.editage.jp) for English language editing.

\section{Authors' contributions}

SM and YM were responsible for the conception and design of the study. SM and YM performed the experiments and analyzed the data. SM, MI, NM, TO, SK and $\mathrm{KO}$ provided intellectual input, laboratory materials, reagents and analytic tools. SM wrote the manuscript. MI, NM, TO, SK and KO revised the manuscript. All authors reviewed and approved the final manuscript. All authors read and approved the final manuscript.

\section{Funding}

This work was supported by the Japan Society for the Promotion of Science [Grants-in-Aid for Scientific Research (B: 16H05804 and B: 18H02332), and a Young Scientists grant (B: 16K18798)]. The funders had no role in study design, data collection and analysis, decision to publish, or preparation of the manuscript.

\section{Availability of data and materials}

The nucleotide sequence of the Kgs-c1 genome is accessible in GeneBank under accession number LC589272.

\section{Ethics approval and consent to participate}

Not applicable.

\section{Consent for publication}

Not applicable.

\section{Competing interests}

The authors declare that they have no competing interests.

\section{Author details}

${ }^{1}$ Department of Disease Control, Faculty of Veterinary Medicine, Hokkaido University, Kita-18, Nishi-9, Kita-ku, Sapporo 060-0818, Japan. ${ }^{2}$ Department of Advanced Pharmaceutics, Faculty of Veterinary Medicine, Hokkaido University, Kita-18, Nishi-9, Kita-ku, Sapporo 060-0818, Japan.

Received: 17 July 2020 Accepted: 15 November 2020

Published online: 23 November 2020

\section{References}

1. Calnek BW, Witter RL. Marek's disease. In: Calnek BW, Barnes HJ, Beard CW, McDougald LR, Saif YM, editors. Diseases of poultry. 10th ed. lowa: lowa State University Press; 1997. p. 369-413.

2. Schat KA. History of the first-generation Marek's disease vaccines: the science and little-known facts. Avian Dis. 2016;60:715-24.

3. Witter RL. Control strategies for Marek's disease: a perspective for the future. Poult Sci. 1988;77:1197-203.

4. Witter RL. Increased virulence of Marek's disease virus field isolates. Avian Dis. 1997;41:149-63.

5. Barrow A, Venugopal K. Molecular characteristics of very virulent European MDV isolates. Acta Virol. 1999:43:90-3.

6. Othman I, Aklilu E. Marek's disease herpesvirus serotype 1 in broiler breeder and layer chickens in Malaysia. Vet World. 2019;12:472-6.

7. Raja A, Dhinakar Raj G, Bhuvaneswari P, Balachandran C, Kumanan K. Detection of virulent Marek's disease virus in poultry in India. Acta Virol. 2009;53:255-60.
8. Shi MY, Li M, Wang WW, Deng QM, Li QH, Gao YL, Wang PK, Huang T, Wei P. The emergence of a $\mathrm{V} v+$ MDV can break through the protections provided by the current vaccines. Viruses. 2020;12:1048.

9. Sun GR, Zhang YP, Lv HC, Zhou LY, Cui HY, Gao YL, Qi XL, Wang YQ, Li K, Gao L, Pan Q, Wang XM, Liu CJ. Chinese variant Marek's disease virus strain with divergence between virulence and vaccine resistance. Viruses. 2017;9:71.

10. Sung HW. Recent increase of Marek's disease in Korea related to the virulence increase of the virus. Avian Dis. 2002;46:517-24.

11. Zhuang X, Zou H, Shi H, Shao H, Ye J, Miao J, Wu G, Qin A. Outbreak of Marek's disease in a vaccinated broiler breeding flock during its peak egg-laying period in China. BMC Vet Res. 2015;11:157.

12. Peng $Q$, Shirazi $Y$. Isolation and characterization of Marek's disease virus (MDV) CDNAs from a MDV-transformed lymphoblastoid cell line: identification of an open reading frame antisense to the MDV ECo-Q protein (Meq). Virology. 1996;221:368-74.

13. Peng $Q$, Zeng M, Bhuiyan ZA, Ubukata E, Tanaka A, Nonoyama M, Shirazi Y. Isolation and characterization of Marek's disease virus (MDV) cDNAs mapping to the BamHI-I2, BamHI-Q2, and BamHI-L fragments of the MDV genome from lymphoblastoid cells transformed and persistently infected with MDV. Virology. 1995;213:590-9.

14. Qian Z, Brunovskis P, Rauscher F III, Lee L, Kung HJ. Transactivation activity of Meq, a Marek's disease herpesvirus bZIP protein persistently expressed in latently infected transformed T cells. J Virol. 1995;69:4037-44.

15. Ross N, O'Sullivan G, Rothwell C, Smith G, Burgess SC, Rennie M, Lee LF, Davison TF. Marek's disease virus EcoRI-Q gene (meq) and a small RNA antisense to ICP4 are abundantly expressed in CD4+ cells and cells carrying a novel lymphoid marker, AV37, in Marek's disease lymphomas. J Gen Virol. 1997;78:2191-8.

16. Liu JL, Kung HJ. Marek's disease herpesvirus transforming protein MEQ: a c-Jun analogue with an alternative life style. Virus Genes. 2000;21:51-64.

17. Deng X, Li X, Shen Y, Qiu Y, Shi Z, Shao D, Jin Y, Chen H, Ding C, Li L, Chen P, Ma Z. The Meq oncoprotein of Marek's disease virus interacts with p53 and inhibits its transcriptional and apoptotic activities. Virol J. 2010;7:348.

18. Brown AC, Baigent SJ, Smith LP, Chattoo JP, Petherbridge LJ, Hawes P, Allday MJ, Nair V. Interaction of MEQ protein and C-terminal-binding protein is critical for induction of lymphomas by Marek's disease virus. Proc Natl Acad Sci USA. 2006;103:1687-92.

19. Shamblin CE, Greene N, Arumugaswami V, Dienglewicz RL, Parcells MS. Comparative analysis of Marek's disease virus (MDV) glycoprotein-, lytic antigen pp38- and transformation antigen Meq-encoding genes: association of meq mutations with MDVs of high virulence. Vet Microbiol. 2004; 102:147-67.

20. Ajithdoss DK, Reddy SM, Suchodolski PF, Lee LF, Kung HJ, Lupiani B. In vitro characterization of the Meq proteins of Marek's disease virus vaccine strain CVI988. Virus Res. 2009;142:57-67.

21. Murata S, Okada T, Kano R, Hayashi Y, Hashiguchi T, Onuma M, Konnai S, Ohashi K. Analysis of transcriptional activities of the Meq proteins present in highly virulent Marek's disease virus strains, RB1B and Md5. Virus Genes. 2011;43:66-71.

22. Murata S, Hashiguchi T, Hayashi Y, Yamamoto Y, Matsuyama-Kato A, Takasaki S, Isezaki M, Onuma M, Konnai S, Ohashi K. Characterization of Meq proteins from field isolates of Marek's disease virus in Japan. Infect Genet Evol. 2013;16:137-43.

23. Padhi A, Parcells MS. Positive selection drives rapid evolution of the meq oncogene of Marek's disease virus. PLoS ONE. 2016;11:e0162180.

24. Lachheb J, Mastour H, Nsiri J, Kaboudi K, Choura I, Ammouna F, Amara A, Ghram A. Newly detected mutations in the Meq oncogene and molecular pathotyping of very virulent Marek's disease herpesvirus in Tunisia. Arch Virol. 2020;165:2589-97.

25. L'opez-Osorio S, Piedrahita D, Espinal-Restrepo MA, Ram irez-Nieto GC, Nair V, Williams SM, Baigent S, Ventura-Polite C, Aranzazu-Taborda DA, Chaparro-Guti errez JJ. Molecular characterization of Marek's disease virus in a poultry layer farm from Colombia. Poult Sci 2017;96:1598-608.

26. Mescolini G, Lupini C, Davidson I, Massi P, Tosi G, Catelli E. Marek's disease viruses circulating in commercial poultry in Italy in the years 2015-2018 are closely related by their meq gene phylogeny. Transbound Emerg Dis. 2020;67:98-107.

27. Mescolini G, Lupini C, Felice V, Guerrini A, Silveira F, Cecchinato M, Catelli E. Molecular characterization of the meq gene of Marek's disease viruses 
detected in unvaccinated backyard chickens reveals the circulation of low- and high-virulence strains. Poult Sci. 2019;98:3130-7.

28. Mohamed MH, El-Sabagh IM, Al-Habeeb MA, Al-Hammady YM. Diversity of Meq gene from clinical Marek's disease virus infection in Saudi Arabia. Vet World. 2016;9:572-8

29. Renz KG, Cooke J, Clarke N, Cheetham BF, Hussain Z, Fakhrul Islam AF, Tannock GA, Walkden-Brown SW. Pathotyping of Australian isolates of Marek's disease virus and association of pathogenicity with meq gene polymorphism. Avian Pathol. 2012;41:161-76.

30. Tian M, Zhao Y, Lin Y, Zou N, Liu C, Liu P, Cao S, Wen X, Huang Y. Comparative analysis of oncogenic genes revealed unique evolutionary features of field Marek's disease virus prevalent in recent years in China. Virol J. 2011:8:121

31. Zhang YP, Liu CJ, Zhang F, Shi W, Li J. Sequence analysis of the Meq gene in the predominant Marek's disease virus strains isolated in China during 2006-2008. Virus Genes. 2011;43:353-7.

32. Spatz SJ, Petherbridge L, Zhao Y, Nair V. Comparative full-length sequence analysis of oncogenic and vaccine (Rispens) strains of Marek's disease virus. J Gen Virol. 2007;88(Pt 4):1080-96.

33. Lee LF, Wu P, Sui D, Ren D, Kamil J, Kung HJ, Witter RL. The complete unique long sequence and the overall genomic organization of the GA strain of Marek's disease virus. Proc Natl Acad Sci USA. 2000;97:6091-6.

34. Niikura M, Dodgson J, Cheng H. Direct evidence of host genome acquisition by the alphaherpesvirus Marek's disease virus. Arch Virol. 2006;151:537-49.

35. Spatz SJ, Rue CA. Sequence determination of a mildly virulent strain (CU2) of Gallid herpesvirus type 2 using 454 pyrosequencing. Virus Genes. 2008;36:479-89.

36. Spatz SJ, Volkening JD, Gimeno IM, Heidari M, Witter RL. Dynamic equilibrium of Marek's disease genomes during in vitro serial passage. Virus Genes. 2012;45:526-36.

37. Spatz SJ, Zhao Y, Petherbridge L, Smith LP, Baigent SJ, Nair V. Comparative sequence analysis of a highly oncogenic but horizontal spread-defective clone of Marek's disease virus. Virus Genes. 2007;35:753-66.

38. Tulman ER, Afonso CL, Lu Z, Zsak L, Rock DL, Kutish GF. The genome of a very virulent Marek's disease virus. J Virol. 2000;74:7980-8.

39. Cheng Y, Cong F, Zhang YP, Li ZJ, Xu NN, Hou GU, Liu CJ. Genome sequence determination and analysis of a Chinese virulent strain, LMS, of Gallid herpesvirus type 2. Virus Genes. 2012;45:56-62.

40. He L, Li J, Zhang Y, Luo J, Cao Y, Xue C. Phylogenetic and molecular epidemiological studies reveal evidence of recombination among Marek's disease viruses. Virology. 2018;516:202-9.

41. Lv H, Zhang Y, Sun G, Bao K, Gao Y, Qi X, Cui H, Wang Y, Li K, Gao L, Pan Q, Wang X, Liu C. Genetic evolution of Gallid herpesvirus 2 isolated in China. Infect Genet Evol. 2017;51:263-74.

42. Su S, Cui N, Cui Z, Zhao P, Li Y, Ding J, Dong X. Complete genome sequence of a recombinant Marek's disease virus field strain with one reticuloendotheliosis virus long terminal repeat insert. J Virol. 2012;86:13818-9.

43. Zhang YP, Bao KY, Sun GR, Lv HC, Cui HY, Gao YL, Wang XM, Liu CJ. Characterization of a Gallid Herpesvirus 2 strain with novel reticuloendotheliosis virus long terminal repeat inserts. Virus Genes. 2017;53:386-91.

44. Zhang F, Liu CJ, Zhang YP, Li ZJ, Liu AL, Yan FH, Cong F, Cheng Y. Comparative full-length sequence analysis of Marek's disease virus vaccine strain 814. Arch Virol. 2012;57:177-83.

45. Spatz SJ, Smith LP, Baigent SJ, Petherbridge L, Nair V. Genotypic characterization of two bacterial artificial chromosome clones derived from a single DNA source of the very virulent gallid herpesvirus-2 strain C12/130. J Gen Virol. 2011;92(Pt 7):1500-7.
46. Trimpert J, Groenke N, Jenckel M, He S, Kunec D, Szpara ML, Spatz SJ, Osterrieder N, McMahon DP. A phylogenomic analysis of Marek's disease virus reveals independent paths to virulence in Eurasia and North America. Evol Appl. 2017;10:1091-101.

47. Machida Y, Murata S, Matsuyama-Kato A, Isezaki M, Taneno A, Sakai E, Konnai S, Ohashi K. Isolation and purification of Gallid herpesvirus 2 strains currently distributed in Japan. J Vet Med Sci. 2017;79:115-22.

48. Murata S, Chang KS, Lee SI, Konnai S, Onuma M, Ohashi K. Development of a nested polymerase chain reaction method to detect oncogenic Marek's disease virus from feather tips. J Vet Diagn Invest. 2007;19:471-8.

49. Parcells MS, Anderson AS, Morgan TW. Retention of oncogenicity by a Marek's disease virus mutant lacking six unique short region genes. J Virol. 1995;69:7888-98.

50. Schat KA, Calnek BW, Fabricant J. Characterization of two highly oncogenic strains of Marek's disease virus. Avian Pathol. 1982;11:593-605.

51. Schat KA, Chen CL, Shek WR, Calnek BW. Surface antigens on Marek's disease lymphoblastoid tumor cell lines. J Natl Cancer Inst. 1982;69:715-20.

52. Katoh K, Standley DM. MAFFT multiple sequence alignment software version 7: improvements in performance and usability. Mol Biol Evol. 2013:30:772-80.

53. Kumar S, Stecher G, Tamura K. MEGA7: molecular evolutionary genetics analysis version 7.0 for bigger datasets. Mol Biol Evol 2016;33:1870-4.

54. Rzhetsky A, Nei M. A simple method for estimating and testing minimum-evolution trees. Mol Biol Evol. 1992;9:945-67.

55. Filipski A, Tamura K, Billing-Ross P, Murillo O, Kumar S. Phylogenetic placement of metagenomic reads using the minimum evolution principle. BMC Genomics. 2015;16(Suppl 1):S13.

56. Spatz SJ, Silva RF. Sequence determination of variable regions within the genomes of gallid herpesvirus-2 pathotypes. Arch Virol. 2007;152:1665-78.

57. Santin ER, Shamblin CE, Prigge JT, Arumugaswami V, Dienglewicz RL, Parcells MS. Examination of the effect of a naturally occurring mutation in glycoprotein L on Marek's disease virus pathogenesis. Avian Dis. 2006;50:96-103.

58. Shaikh SA, Katneni UK, Dong H, Gaddamanugu S, Tavlarides-Hontz P, Jarosinski KW, Osterrieder N, Parcells MS. A deletion in the glycoprotein $\mathrm{L}(\mathrm{gL})$ gene of U.S. Marek's disease virus (MDV) field strains is insufficient to confer increased pathogenicity to the bacterial artificial chromosome (BAC)-based strain, RB-1B. Avian Dis 2013;57(2 Suppl):509-18.

59. Kharkwal H, Smith CG, Wilson DW. Herpes simplex virus capsid localization to ESCRT-VPS4 complexes in the presence and absence of the large tegument protein UL36p. J Virol. 2016;90:7257-67.

60. Veiga IB, Jarosinski KW, Kaufer BB, Osterrieder N. Marek's disease virus (MDV) ubiquitin-specific protease (USP) performs critical functions beyond its enzymatic activity during virus replication. Virology. 2013:437:110-7.

61. Jarosinski K, Kattenhorn L, Kaufer B, Ploegh H, Osterrieder N. A herpesvirus ubiquitin-specific protease is critical for efficient $T$ cell lymphoma formation. Proc Natl Acad Sci USA. 2007;104:20025-30.

62. Takahashi K, Nei M. Efficiencies of fast algorithms of phylogenetic inference under the criteria of maximum parsimony, minimum evolution, and maximum likelihood when a large number of sequences are used. Mol Biol Evol. 2000;17:1251-8.

\section{Publisher's Note}

Springer Nature remains neutral with regard to jurisdictional claims in published maps and institutional affiliations. 